\title{
Non-obligatory Forgiveness: Supererogatory or Impermissible?
}

\section{Rhonda Anderson \\ University of Saskatchewan}

Traditionally, forgiveness has been considered a virtue, and instances of forgiving positive. David Heyd, in his 1982 work Supererogation, contends that "forgiveness is not always obligatory." 1 While acknowledging that all acts of forgiveness are good, he differentiates between those acts of forgiveness which are a duty and those which are not. To Heyd, any act of forgiveness that is not obligatory must be supererogatory. As it stands, Heyd's account of forgiveness is persuasive. Nevertheless, he overlooks the possibility that an act of forgiveness that is not obligatory might be impermissible rather than supererogatory.

Heyd's description of forgiveness contains few surprises. Forgiveness is a reaction to an insult or injury and as such, is an alternative to continued resentment. 2 Generally, forgiving is confined to personal relationships, and includes the restoration of such a personal relationship after a disruption. Undoubtedly, Heyd would insist that resuming the personal relationship involve sincerity rather than show; therefore, forgiveness requires a change of feeling or point of view that would effect the required restoration. Most importantly, forgiveness "presupposes recognition by both parties of the wrongness of the action and its agent's responsibility" (157). He considers non-obligatory forgiveness as supererogatory forbearance, that is, relinquishing one's right or taking less than one's share. Forbearance involves doing more than "is required by

1 David Heyd, Supererogation (Cambridge: Cambridge University Press, 1982) 159. Further references to this text will be cited parenthetically within the essay . 2 The $O E D$ defines resentment as "an indignant sense of injury or insult received. or of wrong or af front done to some person or thing to which one is attached." An obsolete definition is "an appreciation or understanding of something." I would suggest that the second definition is implied because resentment involved the recognition that one has been deliberately injured or insulted. 
the natural duties of mutual help, concern for others, friendliness, and respect" (153).

Heyd does not clarify which acts of forgiveness are obligatory. Although he states that one ought to forgive when one is entitled to harbor resentment for only a short period of time, he does not define any specific criterion for how this time period is to be decided. He also allows that "some people would wish to argue that resentment is never justified if the offender has sincerely asked to be forgiven. For such people, forgiveness is supererogatory only when granted without being asked for" (159). His evoking of "some people" implies his dissociation from such a group. However, one is then left with no practical guidelines as to what Heyd would accept as generating the duty of forgiveness.

One might ask why "some people" hold forgiving to be a duty in the case of the offender's asking to be forgiven. To suggest that such an offender has a right to forgiveness seems contrary to intuition. Can every (or even any) injury or insult, followed by a sincere apology, create such a right? Here, Heyd's remarks on the relation between duty and rights could provide enlightenment. He contends that "many philosophers have conclusively shown [that] not every duty has a corresponding right, i.e. an act may be obligatory even if no one has a 'right' over it" (120). Further, supererogation cannot be identified with the area of duty which lacks corresponding rights "for there are various kinds of duties that do not correspond to rights - some of which have no relation to supererogation" (120). Perhaps repentance creates a good reason for, rather than a right, to forgiveness. By asking to be forgiven, the offender would seem to be saying that the sinner is not the sin. Seen in this light, the sinner joins the victim in condemning the offending act. In such a case, forgiveness may become a duty, performed in the interest of justness and fairness.

If forgiveness in the case of repentance is a duty, despite the lack of a corresponding right, then the obligation must rest on good reasons; perhaps the offender deserves to be forgiven even though he or she has no right to such forgiveness. How is one to decide? In his 1988 article entitled "Moral Subjects, Freedom, and Idiosyncrasy," Heyd advances the notion of idiosyncratic reasons which, he says, is consistent with his remarks in Supererogation. 
His position is that "idiosyncratic reasons, though not derived from the model [of a moral theory] may still be considered rational in light of a plan, a scheme, or a project that is part of a person's life and identity." 3 Such reasons come into play in three areas: forming the basis for choosing a moral point of view (adopting a moral model); governing the way in which moral reasons are applied in practice (within a model); and forming the basis for choosing to act in a supererogatory way (transcending a moral model).At times, features of an agent's character or circumstances become idiosyncratic reasons having moral relevance. To this agent, these reasons are binding on himself or herself, but not on other moral agents. These reasons can relate to the context of the situation ${ }^{4}$ or can "take into account the particular character and identity either of the agent or of the beneficiary of the action (or of both)." 5 Consequently, "we may forgive a friend without binding ourselves to forgive an enemy; we are permitted to have personal biases in selecting the beneficiaries of our supererogatory conduct.' 6 However, although one may be, as he contends, acting on idiosyncratic reasons, it is unclear whether this reasoning is taking place within the model or transcending it.

Heyd contends that forgiveness is optional because it is inconsistent; that is, it is not "constrained [to] treating like cases alike" (159). As long as the resentment is justified, the offender cannot complain that previous similar offenses were forgiven. However, Heyd's appeal to similar cases is deceptive. Admittedly,

3 David Heyd, "Moral Subjects, Freedom and Idiosyncrasy " Human Agency: Language. Duty, and Value, Ed. Jonathan Dancy et al. (Stanford: Stanford University Press, 1988) 155.

4 Heyd, "Moral Subjects. Freedom, and Idiosyncrasy" 158. However . Heyd's example of this contextual reasoning is disappointing, to say the least. He evokes "the king who declares a general amnesty for criminals on the occasion of a military victory or an anniversary [; he] is acting on a reason that is, although impersonal, nonetheless typically idiosyncratic, in that it arises only out of a contingent state of affairs that it neither captured by any moral rule nor based on the model." Such an act might be aesthetically pleasing but I would hesitate to consider it morally good. Any moral benefit deriving from such an act would seem to be incidental rather than intentional.

5 Heyd, "Moral Subjects. Freedom, and Idiosyncrasy" 158.

6 Heyd. "Moral Subjects, Freedom, and Idiosyncrasy” 159. 
a person could forgive an offender for a particular insult but, if the insult recurs, he or she need not forgive it automatically. Yet such withholding may not be inconsistent; the cases are not similar in that one is not a series. Again. if one person is forgiven for an insult, the next offender (of the same act) should not assume forgiveness on the same ground, because rarely do two people stand in exactly the same relationship to the (potential) forgiver or the act. If the cases are similar, and the second offender does stand in exactly the same relationship to both the forgiver and the act, then the offender might be justified in complaining. For example, one child might offend a parent morally and be forgiven; if the next child offends the parent in the same way, he or she may be justified in complaining if he or she is not similarly forgiven. If forced to explain one's seemingly arbitrary decision (not to forgive), one would most probably show that the two cases are only superficially alike rather than suggest that one has a personal bias in selecting one's beneficiary.

Perhaps Heyd is contending that forgiveness is supererogatory only in cases in which the offender has not sought forgiveness. Earlier, he has asserted that forgiveness presupposes that the offender has acknowledged and taken responsibility for the insult or injury. Obviously, this acknowledgment must differ from sincere repentance. Such a distinction, however, does not solve Heyd's difficulty. One would have difficulty understanding an act of forgiveness if the offender admits responsibility, acknowledges the hurtful nature of the act, yet professes indifference to its harmful effect. Although not impossible, such a case seems unlikely. Instead, one would assume that she would take responsibility for the hurtful act yet attempt to account for it in some fashion. One must then decide whether, in a particular case, forgiveness is permissible. If not permissible, then one could say that the forgiver has done something wrong. But if permissible, then, given that each case must rest on grounds other than the offender's right to forgiveness, one can no longer clearly see how such a case might differ from the case of sincere repentance. In other words, if it is permissible and obligatory to forgive in the case of repentance, then surely other good reasons might also serve as the basis for obligations. For instance, one might forgive because the friendship with the 
offender is of such duration that the offending act seems aberrant rather than typical behaviour. Consequently, the friend might have acceptable (though undisclosed) reasons for her action.

Finally, Heyd contends that "an act of...forgiveness...which is undeserved may be called saintly since, as in other saintly acts of supererogation, we feel that we are not in a position even to encourage or to urge the agent to supererogate" (163). Heyd can hold this position because he contends that acts of forgiveness are permissible. For Heyd, the concept of permissibility is "employed to bridge the conflicting views we might have regarding the deontic status for example of forgiveness or gratitude, which are one the one hand thought to be a moral duty, yet are also felt to be optional in a way other moral duties are not" (121).

In any case, to say that acts of forgiveness are permissible does not mean that every act of forgiveness is permissible. In Forgiveness and Mercy, Jeffrie Murphy, like Heyd, defines forgiveness as a giving up of resentment; however, he goes further than Heyd by contending that resentment is a reaction to a moral injury to one's self-respect. He concludes that the consequence of resentment can often be beneficial rather than detrimental. To forgive too readily may signal one's lack of self- respect. Not to resent "when our rights are violated is to convey-emotionally-either that we do not think we have rights or that we do not take our rights very seriously. Forgiveness may indeed restore relationships, but to seek restoration at all cost-even at the cost of one's human dignitycan hardly be a virtue.' 7 In other words, resentment is a reaction to a moral injury, and when one chooses to forgive or not forgive, one does so for moral reasons. Moreover, "if it is proper to feel indignation when [one] see[s] third parties morally wronged, must it not be equally proper to feel resentment when [one] experience[s] the moral wrong done to [oneself]?'8

Murphy concludes that "forgiveness is acceptable only in cases where it is consistent with self-respect, respect for others as responsible moral agents, and... [where it does] not involve

7 Jeffrie G. Murphy, "Forgiveness and Resentment," Forgiveness and Mercy (Cambridge: Cambridge University Press, 1988) 17.

8 Murphy 18. 
complicity or acquiescence in wrongdoing." 9 Similarly, other writers cite cases in which forgiveness is not permissible. Joanna North, in her 1987 essay "Wrongdoing and Forgiveness," argues that "forgiveness requires that a wrong not be disregarded, overlooked, or dismissed" (502). She concludes that such willful blindness may indicate moral weakness.

Jean Hampton in Forgiveness and Mercy, argues that forgiveness can sometimes be confused with the related concept of 'condonation.' 10 She defines condonation as "the acceptance, without moral protest (either inward or outward), of an action which ought to warrant such protest, made possible, first, by the ridding oneself of the judgement that the action is wrong, so that its performer cannot be a wrongdoer, and, second, by ridding oneself of any attendant feelings (such as those which are involved in resentment) which signify one's protest of the action" (40). The decision to "treat the action as not being wrong" would seem to contradict Heyd's claim that forgiveness presupposes the wrongness of the action. Yet Hampton's examples suggest that the action is deemed 'not wrong' because of extenuating circumstances, such as a lack of clarity about either the offender's intention or the circumstances surrounding the action. Thus, the resentment is overcome (perhaps even for moral reasons such as the peace of the family or love), and personal relationships may be restored, but one is condoning rather than forgiving. Hampton argues that the close alliance between the acts of forgiving and condoning suggests that the conceptual model of forgiveness is at fault. However, another possible interpretation of her examples is that forgiveness is not always permissible. According to Heyd, when one says that a person is wrong to forgive someone, one usually means "that [the offender] did not deserve to be forgiven, rather than that [the forgiver] did something wrong or blameworthy" (158). I believe that the varying views of these philosophers suggest that Heyd is

\section{Murphy 19.}

10 The $O E D$ defines 'condone' as "to forgive or overlook (an of fence): especially to forgive tacitly by not allowing the of fence to make any difference in one's relations with the of fender." Since Hampton differentiates between condoning and forgiving, I am assuming that she is emphasizing the notion of overlooking. 
mistaken. When we say that a person errs in forgiving someone, we are implying that the forgiver is at fault.

Unlike these other writers, Heyd makes no subtle distinctions between individual acts of forgiving, maintaining that forgiveness is always permissible. For Heyd, "resentment-even if it is justified - is never a virtue; forgiveness - even if it is undeserved is always a virtue" (162). In his view, forgiveness, being a "shift from one level of relationship to another[,] is morally permitted and valuable because it is not unjust, because it is good and altruistic (the only possible loser being the agent of the act, although unlike other cases of sacrifice, the forgiving party cannot strictly speaking be described as losing anything)" (162). Heyd's view, however, puts forgiveness too squarely in the private realm, where justice has traditionally been ignored.

Heyd and the other writers cited here appear to suggest that resentment is easy whereas forgiveness is always difficult. Yet I would suggest that the opposite holds true. Self-respect is particularly vulnerable to attack and, although a person can feel the initial resentment, he or she may be less than sanguine about feeling justified in holding such resentment. Especially within personal relationships, forgiveness might seem easier than insistence on a right that one is not even certain one has.

Several examples might suggest that Heyd's view of forgiveness is too benign. The case of physical abuse within marriage provides one such example. A woman might initially resent this injury, so much so that she turns to the judicial system. However, out of love and her husband's acknowledgement and readiness to take responsibility for this hurtful action, she might forgive the beating and abort the legal process. The chances are excellent that she will later regret her act of forgiveness. Such a case, of course, no longer arises because the law has now been made more stringent. The woman is no longer allowed the option of speedy forgiveness because, if called upon to intervene, The Crown accepts responsibility for continuing the process. This change has come about not only because of increased understanding about the nature of spousal abuse, but also because we recognize the level of respect due to a woman within the confines of marriage. Repeated acts of 
forgiveness can damage a woman's self-esteem severely; therefore, she could be described as losing something by her forgiveness.

Nor can it be said that the one injured is the only one affected by an act of forgiveness. For example, one might consider a case of sexual harassment in an office. The woman initially resents the behaviour but forgives it (perhaps because the offender acknowledges the wrong yet confesses to being unable to stop the behaviour). Her forgiveness might affect the other women in the office. The offender might, for instance, harass another woman whose subsequent complaint will be countered with the information that other women either do not seem to mind, or if offended, nevertheless respond less vindictively. One might also consider the attempt to unionize a workplace which has been operating on a paternalistic system. A worker might be arbitrarily forced to work overtime. The employer might acknowledge the wrong, but remind the worker of past benefits. If the worker forgives her employer, she might, in the process, be failing in her obligation to her fellow workers. The history of union activity is filled with such tales.

Harriet Beecher Stowe's Uncle Tom 's Cabin, once considered the classic novel of forgiveness, is no longer viewed benignly. Modern sensibilities contend that Tom's actions constitute race betrayal and mimicry, and 'Uncle Tom' is now a pejorative term. However personal, acts of moral injury and forgiveness do not take place in a vacuum. The claims of justice are surely as relevant in the personal as in the public sphere. The act of forgiveness is not, as Heyd contends, always "continuous with justice rather than duty," especially when used as an alternative to, rather than as a corrective of, justice (163).

Norvin Richards, viewing forgiveness and its alternatives as displays of character in his 1988 essay "Forgiveness," holds that forgiveness is not always permissible. When permissible, it can be either obligatory or supererogatory. The act is supererogatory if one's resentment rests on something other than a character defect in oneself (for instance, a valid level of self-respect), yet one chooses not to act on that resentment. One might forgive because one aspires "to be more than merely acceptably kind, or more generous than a person need be to rise above the miserly. Such aspirations need not collapse into narcissism or involve ignoring traits in greater need 
of attention" (82). The difficulty with this view, of course, is its emphasis on the forgiver to the exclusion of both the relationship and the one forgiven. John Wilson, although he does not deal with this aspect of forgiveness in his essay "Why Forgiveness Requires Repentance," therein suggests a point which should be kept in mind. He contends that moral insult or injury involves a breach of trust, and asserts further that "restoration of trust necessarily involves the restoration of an agreement, which cannot be a unilateral affair" (534, Wilson's emphasis). Unlike Wilson, I have suggested that more than involving two people, forgiveness and resentment can involve one's community as a whole. An act of forgiveness is not always permissible because, although improving one's character is a virtue, this improvement cannot be done at the expense of others.

David Heyd's position is that forgiveness is always permissible and that, when it is not a duty, it is supererogatory. However, if forgiveness rests on something other than the right of the offender, one must ask how dutiful forgiveness can be separated conceptually from supererogatory forgiveness. Moreover, one can quarrel with the notion that forgiving is always permissible. If a particular act of forgiveness is not permissible, it cannot be supererogatory if performed. Although one would hesitate to endorse easy indignation, one could nevertheless allow that forgiveness is not always a virtue. 